\title{
LETTERS
}

\section{Reflecting on my experience after coronary artery bypass grafting}

I am prompted to respond to the CMAJ article "Management of Patients After Coronary Artery Bypass Grafting Surgery: A Guide for Primary Care Practitioners."

I compared my own experience 14 months ago, when I had double bypass surgery, with the typical outcomes detailed in the article.

I was not readmitted within 30 days, as occurs in patients older than 80 years (I was 81).

I did not develop cardiac tamponade, which occurs in $1 \%-12.6 \%$ of patients.

I did not have a perioperative myocardial infarction, which occurs in $0.6 \%-19 \%$ of patients.

I have not had a graft occlusion, which occurs in $2 \%-5 \%$ of patients per annum.

I did not develop pneumonia, which occurs in $2.4 \%$ of patients.

I did not have any cognitive dysfunction, which affects $50 \%-70 \%$ of patients. I did not develop depression, euphoria or anxiety.

I did not have postoperative delirium, which affects $73 \%$ of patients.

I did not develop kidney dysfunction, which affects $30 \%$ of patients.

I did not develop atrial fibrillation, which affects $30 \%$ of patients.

Not seeing a general practitioner (GP) within 30 days is associated with 5 times worse outcomes. I did not get to see my GP within 30 days because of the COVID-19 pandemic, and have not seen her yet, although I have had the best possible care by telephone.

It therefore appears that my outcome was remarkably good, for which I am very thankful. Two factors may have helped: for an electrophysiology study, I was kept in hospital an extra 4 days; then, for 5 days, I had phone access to a skilled nurse practitioner.

This leads me to 2 reflections.

1. I am happy I was not aware of the possible outcomes described in the article, as I would have been full of trepidation.

2. I actually had complications not mentioned by the authors in their literature review, which focused on dire outcomes. These were as follows:

a) Pain on coughing or sneezing which, I was informed, might have been a result of minor cracks in my ribs.

b) Dehiscence of a leg wound - the site of harvest of my left saphenous vein graft, which took 4 months to heal.

c) Electric shock feelings in the lower left leg, which went on for 9 months and were attributed to nerves being cut during the saphenous harvesting.

d) Swelling of the lower left leg, which I am told is permanent, although now minimal.

e) Feelings of light-headedness when walking; it was discovered I had developed iron-deficiency anemia.
Thus, I have 4 suggestions:

1. Coronary artery bypass grafting has a very complex recovery period and the GP should have ongoing, rapid access to the cardiologist and surgeon.

2. Although surgeons have a legal responsibility to inform patients of potential risks, carrying out that responsibility in detail may have negative impact and should be done cautiously.

3. Postoperative hospital stays should be at least a week.

4. During the first week after discharge, there should be daily follow-up by phone with the cardiology team.

\section{J. Joel Jeffries MA MBBCh}

Retired psychiatrist, formerly Centre for Addiction and Mental Health, Toronto, Ont.

Cite as: CMAJ 2021 September 13;193: E1432. doi: 10.1503/cmaj.79961

\section{Reference}

1. de Waard D, Fagan A, Minnaar C, et al. Management of patients after coronary artery bypass grafting surgery: a guide for primary care practitioners. CMAJ 2021;193:E689-94.

Competing interests: None declared.

Content licence: This is an Open Access article distributed in accordance with the terms of the Creative Commons Attribution (CC BY-NC-ND 4.0) licence, which permits use, distribution and reproduction in any medium, provided that the original publication is properly cited, the use is noncommercial (i.e., research or educational use), and no modifications or adaptations are made. See: https://creativecommons.org/ licenses/by-nc-nd/4.0/ 